\title{
Uncertainties in Flow Duration Curves in anthropized catchments
}

\author{
G. Becciu ${ }^{1} \&$ C. Dresti ${ }^{2}$ \\ ${ }^{1}$ Milan Polytechnic, Italy \\ ${ }^{2}$ National Research Council, Institute of Ecosystem Study, Italy
}

\begin{abstract}
Flow Duration Curves (FDC) are a traditional tool in water resources management. Their applications range from environmental protection planning to hydrosystems design. In many problems natural FDC are needed, that is curves referring to river regimes before alterations due to anthropic water uses.

Estimation of FDC, as known, is uncertain in ungauged catchments. Also in gauged catchments, however, uncertainty may be relevant if available flow data are few or recorded after the anthropic alterations were set. This uncertainty may be high in mountain rivers, whose regime is typically more irregular and with significant alterations, mostly due to withdrawals for hydropower uses.

The scope of this paper is to analyze these uncertainties, using a methodology to link anthropic uses to FDC alterations. Application to a catchment in the southwestern Alps is finally presented.

Keywords: Flow-Duration Curves, hydrological alterations, hydrological uncertainties.
\end{abstract}

\section{Introduction}

In recent years, the assessment of uncertainty in hydrology and the analysis of its possible effects on hydrological modelling has become an important issue [1,2]. A unique definition of uncertainty is hard to find in literature, being influenced by the perspective from which it is seen [3]. Referring to its ontological meaning, it can be associated to the impossibility to describe or to measure exactly the present or the future state(s) of a system. This definition is then strongly associated to the concepts of "model" and "measure" of a system and, consequently, also to the concept of "outcome". 
In 2008, Gotzinger and Bardossy [4] identified the main sources of uncertainty in hydrological modelling: i) uncertainty in measurements; ii) uncertainty in the parameters of the model; iii) uncertainty in model structure, due to inherent simplification of more complex real systems.

The first cause of uncertainty mainly relies on difficulties to measure and to model precipitation. Its temporal and spatial heterogeneity make it necessary to consider average values that causes uncertainties in modelling and forecasting catchment water balances and river flow rates [5-7]. More, uncertainty may be also associated to possible non-stationarity of hydrological systems, due to the climate change $[8,9]$ and to anthropic modification of soil use and of hydrographic network.

The second and third causes are mainly related to the limited availability of hydrological data records. This limitation, that is encountered both at space and time scales, makes it necessary to develop simplified models that have to be calibrated in order to get the "best fitting" to observations. Regional model are commonly developed to overcome the lack or scarcity of data records.

The aim of this paper is analyzing the sources of uncertainty in the estimation of flow duration curves. Flow Duration Curves (FDCs) are a traditional tool widely used in water resources development and management. The FDC for a river section provide, usually in graphical or tabular form, the percentage of time in a year (duration) a daily or monthly streamflow is exceeded on average. Empirical FDCs are constructed from streamflow observations using various procedures, i.e. using standardised non-parametric procedures [10,11].

Considering the streamflow as a random variable, the FDC may be interpreted as its sample cumulative frequency function. Methods from probabilistic analysis can be used to fit parametric functions that mathematically express the duration (i.e. the probability) of mean streamflows (i.e. quantiles).

Although all the sources of uncertainties in hydrological modelling should be considered, a great source of uncertainty in FDC estimation is the effect of anthropization on river discharges. The paper will focus in particular on this last aspect, considering the variations in river flow regime due to urbanization, water withdrawals and inter-catchment water exchanges, reservoirs.

\section{Anthropization effects on river flow regime}

The flow regime of mountain rivers depends on the combination of three main components: surface runoff during the most intense storm events, snowmelt and flow exchange between riverbed and groundwater [14, 15].

Net rainfall transformation in surface runoff depends mainly on the climatic context, catchment geomorphologic characteristics, land uses and soil water content. Higher river discharges are due to surface runoff during flood events and influence the left tail of FDCs. The flashier the river floods, as typically happens in small mountain catchments, the steeper this tail. Extension of this tail in mean annual FDC for catchments with no or negligible anthropic alterations is approximately equal to the mean number of rainy days in a year. 
Melting of snow covers or glacier is limited to late spring and summer and it is obviously variable with temperatures and radiation. Effects on river discharges are significant and in some cases may be comparable to those in flood events. However, the process is more gradual and the related discharges are in most cases smaller. The influence of this component is more on the central part of FDCs, which is less steep than the left tail.

Flow exchange between river and groundwater is variable both in time and in space. Although, in some conditions, the river may lose water to the groundwater, during dry weather the flow balance is on average in favour of the river and baseflow discharges are mainly due to this component. The discharges during the dry weather are generally less variable and decrease exponentially, with rates depending on the geological characteristics of the catchment (recession flow). Infiltration into the soil during storm events, however, modifies groundwater levels and time patterns of flow to the river. Influence of river-groundwater exchange is then strong on smaller flows and may be significant on mean flows. The right tail of FDCs is the affected by the combination of flows from recession periods with different characteristics.

Frequency distribution of river flows due to the three components are similar. The higher values in the left tail may be considered as extremes and they are described by probability distributions functions with an exponential tail, like e.g. the Gamma, the Weibull or the Exponential itself. In the other parts of the curve, flows are due to the combination of snowmelt and groundwater exchange, processes that typically are characterised by an exponential decay and a certain degree of autocorrelation [16]. Except for the extreme right tail of FDCs, the ranking procedure produce a mixing of flows from different decay periods, which results in a probability distribution function with an exponential tail.

Anthropic activities may alter river flows in different ways. Diversions and withdrawals change directly the mean runoff. In this way, the water availability for human and ecosystems uses changes. Other human activities may affect mainly the flow variability in time, such as regulating structures like dams and barrages. In general, it is possible to say that significant flow regulation leads to a change in FDCs shape, which becomes flatter respect to the natural case, with an attenuation of higher flows (floods) and an increase of low flows [17].

Leopold, in 1968 [18], and Stephenson, in 1994 [19] group in three main categories the impacts on river flow due to anthropic activities: 1) effect on the long-term water balance at the catchment scale (long-term variability); 2) variation from year to year of the statistics of river flow (inter-annual variability); 3) intraannual variation of river flow.

\subsection{Variability of long-term water balance}

Water balance evaluations are important in climate research and biosphere studies, since they provide important information regarding water circulation in the hydrological cycle and the amount of renewable water available for ecosystems and humans [6]. Assuming that the total water content in the catchment is the same, on average, both at the beginning and at the end of an annual cycle, the longterm annual water balance for a catchment can be expressed as [14]: 


$$
P-E T-Q-I_{D}=0
$$

where:

$P=$ precipitation;

$E T=$ effective evapotranspiration;

$Q=$ surface runoff;

$I_{D}=$ deep underground runoff, not contributing to $Q$ in the catchment outlet section.

The terms in equation (1) are long-term mean annual volumes, usually expressed per unit area of catchment. Precipitation is the only climate variable measured directly on a regular basis, while evapotranspiration is usually estimated. Deep underground runoff is sometimes neglected, having usually values of the same order of the errors in rainfall and flow measurements, or assumed equal to a fixed percentage.

If the mean annual runoff coefficient $\bar{\varphi}$ is introduced,

$$
\bar{\varphi}=1-\frac{E T+I_{D}}{P}
$$

the annual runoff $Q$ may be considered as a random variable, product of two random variables, $P$ and $\bar{\varphi}$.

$$
Q=\bar{\varphi} \cdot P
$$

Uncertainty in the estimation of $Q$ can then be related to the uncertainties of precipitation and mean annual runoff coefficient. In particular, Fekete and Vorosmarty [6] demonstrated that the uncertainty in precipitation translates to at least same but in general much greater uncertainty in runoff in relative terms.

If $P$ and $\bar{\varphi}$ are assumed to be independent (or better, if their correlation is neglected) and a FOSM (First Order Second Moment) approximation is considered, the main moments of $Q$ may be expressed by the following relationships:

$$
\begin{gathered}
E[Q]=E[\bar{\varphi}] \cdot E[P] \\
\operatorname{var}[Q]=\operatorname{var}[\bar{\varphi}] \cdot E^{2}[P]+\operatorname{var}[P] \cdot E^{2}[\bar{\varphi}]+\operatorname{var}[\bar{\varphi}] \cdot \operatorname{var}[P]
\end{gathered}
$$

Anthropic alterations have effects mainly on mean annual runoff coefficient $\bar{\varphi}$. Changes in soil use, like urbanization and deforestation, increase both mean value and variance of $\bar{\varphi}$. Water withdrawals have no effects on $\bar{\varphi}$, although they change local runoff, while reservoirs increase both evaporation and infiltration and so cause a decrease of $\bar{\varphi}$.

\subsection{Inter-annual flow variability}

Anthropic alterations of catchments usually show their effects gradually in time. The natural inter-annual variability of flow regimes can then mask these effects in 
the first times. Detection of these effects can be performed by trend test on annual mean and variance of streamflows, e.g. the Mann-Kendall test [20, 21]. It has to be noted, however, that similar effects could be produced by the climate change, making it difficult in some cases to distinguish between the two causes.

In most of cases, the observed trends are approximately linear, due to the gradualness of changes. Considering a series of $N$ years of streamflow records, the main annual statistics, that is the annual mean and standard deviation, after $i$ years can be expressed as:

$$
\begin{gathered}
m_{q, i}^{*}=a_{m}+b_{m} \cdot i=m_{q}+b_{m} \cdot\left(i-\frac{N}{2}\right) \\
s_{q, i}^{*}=a_{s}+b_{s} \cdot i=s_{q}+b_{s} \cdot\left(i-\frac{N}{2}\right)
\end{gathered}
$$

where $m_{q}$ and $s_{q}$ are the streamflow sample mean and standard deviation estimated in the series of $\mathrm{N}$ years. Once possible trends in the annual statistics were identified, equations (6) and (7) can be used to correct the streamflow records in order to get a stationary sample or simply to take into account the un-stationarity of the record series in the estimation of the mean streamflow quantile, as explained in the next section.

\subsection{Intra-annual flow variability}

Intra-annual flow variability is modified by water withdrawal and storage. In most of cases, anthropic alterations of natural flows have an annual pattern. While water withdrawals change the mean of streamflows, storage facilities change their variance, in some cases significantly [22].

In general, the variance of flows modified by a regulated reservoir $q_{A}$ is lower than the variance of the natural flows $q_{N}$. Although, a precise quantification of this reduction is difficult, due to reservoir management rules that can change in time, an approximate relationship between the variances of $q_{A}$ and $q_{N}$ can be developed [23].

The ratio $R_{V}$ between the two variances, of regulated and natural flows, ranges between 0 and 1 and depends on the amount of catchment area in which flows are regulated $S_{R}$ and on the total active storage in regulating structures $W_{R}$. If a maximum effective value $W_{R \max }=\max \left(W_{R}\right)$ is defined as the active storage needed to have a constant regulated flow, the following relationship may be written [20]:

$$
R_{V}=\frac{\operatorname{var}\left[q_{A}(t)\right]}{\operatorname{var}\left[q_{N}(t)\right]}=\left(1-\left(\frac{S_{R}}{S_{\text {tot }}}\right)^{c_{1}} \cdot\left(\frac{W_{R}}{W_{R m \mathrm{ax}}}\right)^{c_{2}}\right)
$$

Although $W_{R \max }$ depends on the time series of natural flows, its upper limit is equal to the runoff cumulated for all the natural streamflows greater than or equal to their mean, that is for $q_{N}(\mathrm{t}) \geq \mathrm{E}\left[q_{N}(\mathrm{t})\right]$. The ratio $R_{V}$ is equal to one when $S_{R}=0$ or $W_{R}=0$ and is equal to 0 when $S_{R}=S_{\text {tot }}$ and $W_{R}=W_{R \max }$. The exponents $c_{1}$ and $c_{2}$ can be considered as calibration parameters. When no data are available for calibration, the values $c_{1}=0.5$ and $c_{2}=1$ may be assumed [23]. 


\section{Uncertainties in FDC estimation}

Uncertainty in FDC estimation is the combination of flow regime alteration due to anthropization and intrinsic variability due to sample effects. The first effect can be taken into account using the relationships reported in the above section to correct the main statistics of the mean streamflow.

Inter-annual variability due to sample induces an uncertainty in the estimation of the mean FDC that is inversely proportional to the number $N$ of years in the record series. This uncertainty may be taken into account considering the confidence limits of the mean quantile $Z_{\theta}$ corresponding to the duration $\theta$ :

$$
Z_{\theta}=E\left[q_{\theta, i}\right]=\frac{1}{N} \cdot \sum_{i=1}^{N} q_{\theta, i}
$$

where $q_{\theta, i}$ is the streamflow of duration $\theta$ recorded in the $i$-th year. $Z_{\theta}$ is defined also as (365- $\theta$ ) th order statistic of the $i$-th annual sample of recorded streamflows. Considering that $q_{\theta, i}$ for an assigned duration $\theta$ are independent, its variance can be expressed as:

$$
\operatorname{VAR}\left[Z_{\theta}\right]=\frac{1}{N} \cdot \operatorname{VAR}\left[q_{\theta, i}\right]
$$

For the generic $i$-th year, the inverse of the cumulative distribution function of $q_{\theta, i}$ can be expressed as [14]:

$$
q_{\theta, i}=m_{q, i}+K_{T} \cdot s_{q, i}
$$

where $m_{q, i}$ and $s_{q, i}$ are the sample mean and standard deviation of streamflows for that year. $K_{T}$ is the so-called frequency factor, that is a function of return period $\mathrm{T}$ or, that is the same, of the non-exceedance probability. The form of $K_{T}$ depends on the cumulative distribution function assumed for the streamflows. For normal distributions, the frequency factor $K_{T}$ is the standard normal variate $z$. The variance of $q_{\theta, i}$ in the case of normal distribution is [24]:

$$
\begin{aligned}
& \operatorname{VAR}\left[q_{\theta, i}\right]=\operatorname{VAR}\left[m_{\theta, i}\right]+K_{T}{ }^{2} \cdot \operatorname{VAR}\left[s_{\theta, i}\right]+2 \cdot K_{T} \cdot \rho_{m s} \cdot \sqrt{\operatorname{VAR}\left[m_{\theta, i}\right] \cdot \operatorname{VAR}\left[s_{\theta, i}\right]}= \\
& =\frac{\sigma_{q}^{2}}{N}+K_{T}^{2} \cdot \sigma_{q}^{2} \cdot\left(1-\left(\frac{2}{N-1}\right) \cdot\left(\frac{\Gamma\left(\frac{N}{2}\right)}{\Gamma\left(\frac{N-1}{2}\right)}\right)^{2}\right]+2 \cdot K_{T} \cdot \rho_{m s} \cdot \sigma_{q}^{2} \sqrt{\frac{1}{N} \cdot\left[1-\left(\frac{2}{N-1}\right) \cdot\left(\frac{\Gamma\left(\frac{N}{2}\right)^{2}}{\Gamma\left(\frac{N-1}{2}\right)}\right] \cong\right.} \\
& \sigma_{q}^{2} \cdot\left[\frac{1}{N}+\frac{K_{T}^{2}}{2 \cdot N}+\frac{2 \cdot \rho_{m s} \cdot K_{T}}{\sqrt{2} \cdot N}\right]
\end{aligned}
$$

where $\sigma_{q}^{2}$ is the variance of streamflows. Applying the method of moments, the variance and the mean of streamflows can be estimated by the corresponding sample moments: 


$$
\begin{aligned}
& \sigma_{q}{ }^{2}=s_{q}{ }^{2}=\frac{1}{N} \cdot \frac{1}{365} \cdot \sum_{i=1}^{N} \sum_{\theta=1}^{365}\left(q_{\theta, i}-\mu_{q}\right)^{2} \\
& \mu_{q}=m_{q}=\frac{1}{N} \cdot \frac{1}{365} \cdot \sum_{i=1}^{N} \sum_{\theta=1}^{365} q_{\theta, i}=\frac{1}{365} \cdot \sum_{\theta=1}^{365} Z_{\theta}
\end{aligned}
$$

The correlation coefficient $\rho_{m s}$ between the sample mean $m_{q, i}$ and standard deviation $s_{q, i}$ for the $N$ years of records is usually very high.

Using equations (6), (7), (9), (10) is possible to combine all the inter-annual effects of anthropic alterations in the estimation of the streamflow mean quantile $Z_{\theta}$ :

$$
Z_{\theta}=m^{*}{ }_{q}+K_{T} \cdot s_{q}^{*}=f_{1}\left(K_{T}\right)+f_{2}\left(K_{T}\right)
$$

where

$$
\begin{array}{lr}
f_{1}\left(K_{T}\right)=m_{q}+K_{T} \cdot s_{q} & \text { stationary component } \\
f_{2}\left(K_{T}\right)=\left(b_{m}+K_{T} \cdot b_{S}\right) \cdot\left(1-\frac{N}{2}\right) & \text { inter-annual non-stationarity }
\end{array}
$$

To take into account also sample uncertainty, confidence limits of $Z_{\theta}$ are calculated as:

$$
Z_{\theta}=m_{q}^{*}+K_{T} \cdot s{ }_{q} \pm z_{\alpha} \cdot \sigma_{Z}=f_{1}\left(K_{T}\right)+f_{2}\left(K_{T}\right) \pm z_{\alpha} \cdot s_{q} \cdot f_{3}\left(K_{T}\right)
$$

where

$$
f_{3}\left(K_{T}\right)=\left[\frac{1}{N}+\frac{2 \cdot \rho_{m s} \cdot K_{T}}{\sqrt{2} \cdot N}+\frac{K_{T}^{2}}{2 \cdot N}\right]^{1 / 2} \quad \text { sample uncertainty }
$$

Equations (5) and (8) can be used to take into account also the effects of longterm and inter-annual anthropic alteration on the sample standard deviation $s_{q}$ due to soil use and climate changes and regulated storages:

$s_{q A 1}=C_{u} \cdot S_{t o t}^{2} \cdot\left(\sigma_{\bar{\varphi}}^{2} \cdot \mu_{P}^{2}+\mu_{\bar{\varphi}}^{2} \cdot \sigma_{P}^{2}+\sigma_{\bar{\varphi}}^{2} \cdot \sigma_{P}^{2}\right)^{1 / 2}$ effects of soil use and of climate

$s_{q}=s_{q A}=s_{q A 1} \cdot\left(1-\left(\frac{S_{R}}{S_{t o t}}\right)^{c_{1}} \cdot\left(\frac{W_{R}}{W_{R \max }}\right)^{c_{2}}\right)^{1 / 2}$ effect of regulated storages

\section{Case study}

The catchment of the Adda River at the gauging station of Fuentes, in the southwest Alps, was used as a case study for the proposed methodology. A complex system of dams, built for hydropower production in the first half of XX century, and water withdrawals. In Table 1, the main characteristics of River Adda at Fuentes are shown. 
Table 1: Main features for River Adda, Fuentes.

\begin{tabular}{|c|c|c|c|c|c|}
\hline River & Section & $\begin{array}{c}\text { Regulated } \\
\text { area } \\
\mathrm{S}_{\mathrm{R}}\left(\mathrm{km}^{2}\right)\end{array}$ & $\begin{array}{c}\text { Total area } \\
\mathrm{S}_{\mathrm{tot}}\left(\mathrm{km}^{2}\right)\end{array}$ & $\begin{array}{c}\text { Total reservoir } \\
\text { active storage } \\
\mathrm{W}_{\mathrm{R}}\left(10^{6} \mathrm{~m}^{3}\right)\end{array}$ & $\begin{array}{c}\text { Maximum } \\
\text { active storage } \\
\mathrm{W}_{\mathrm{RMAx}}\left(10^{6} \mathrm{~m}^{3}\right)\end{array}$ \\
\hline Adda & Fuentes & 818 & 2598 & 416 & 897 \\
\hline
\end{tabular}

Daily flow records are available for the period 1926-2000, with some gaps in the series. Flow recorded in the years before 1936 can be considered as natural, since most of the great dams have been completed after that year. Records after year 1963 are affected by a variable additional runoff from River Spoel, a tributary of River Inn, due to an International Agreement between Swiss and Italy.

In Figure 1, the mean Flow Duration Curves (FDCs) for the three period (from 1926 to 1935; from 1936 to 1963; after 1963), are presented in a semi-logarithmic plot.

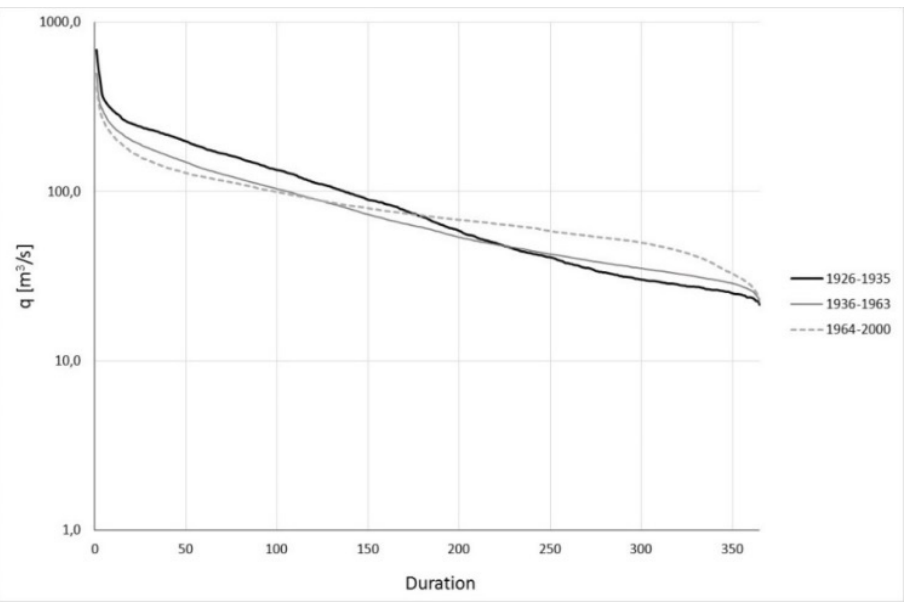

Figure 1: FDCs for river Adda at Fuentes for the periods 1926-1935, 19361963, 1963-2000.

It is possible to notice that the steepness of the curves decreases from the first to the last period. This is an expected result, since reservoirs and in general regulation of river flows produce a decreasing of the variance in the recorded flows and a decreasing of the steepness of FDCs [17].

In Figure 2, the tendency of $\mathrm{m}_{\mathrm{q}}$ and $\mathrm{s}_{\mathrm{q}}$ during the whole period (sample mean and standard deviation for each year) is reported. The Mann-Kendall test was carried out to verify the presence of trend in the mean and standard deviation. While the hypothesis of no trend cannot be rejected for the mean $m_{q}\left(\tau / \operatorname{VAR}[\tau]^{1 / 2}\right.$ $=0.88)$, a decreasing trend of the standard deviation $s_{q}$ seems confirmed $\left(\tau / \operatorname{VAR}[\tau]^{1 / 2}=-2.12\right)$. 


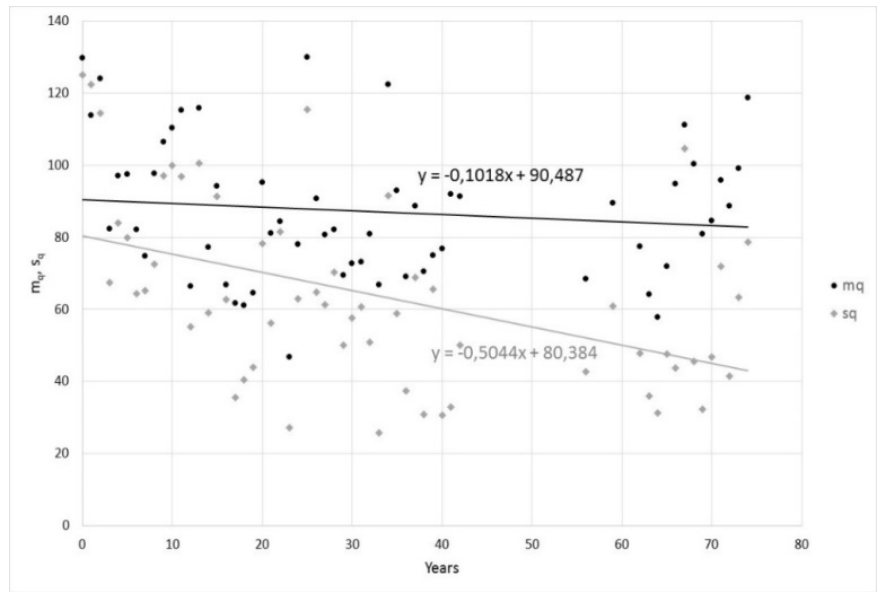

Figure 2: $\quad$ Trend of $m_{q}$ and $s_{q}$ (sample mean and standard deviation) during the years.

Figure 2 shows that $m_{q}$ presents a decreasing trend, which is little significant. The small reduction in the annual mean can be due to climatic factors. On the contrary, the standard deviation $s_{q}$ presents a more important decreasing trend and this is in agreement with the above mentioned effects produced by reservoirs.

To test the hypothesis of normal distribution of annual quantiles $q_{\theta, i}$, their skewness was analyzed for the three periods (Figure 3).

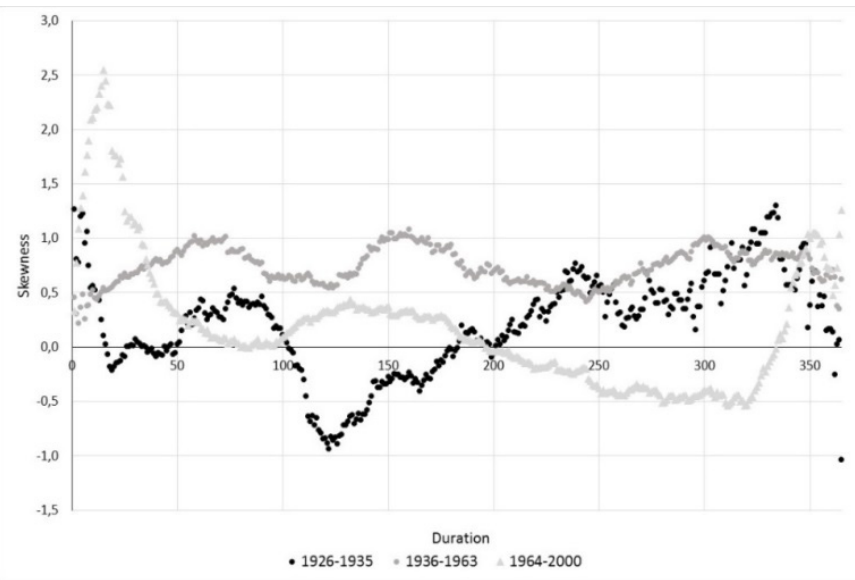

Figure 3: $\quad$ Skewness for $q_{\theta}$ in the three periods: 1926-1935, 1936-1963, 19642000 .

It is possible to notice that the value of skewness are always positive for the period 1936-1963, while they range between -1 and around 1 for the natural records. As regards the period 1964-2000, skewness is quite high for the lowest 
and highest durations. The hypothesis of normal distribution for quantiles $\mathrm{q}_{\theta, \mathrm{i}}$ seem to hold approximately only for natural streamflows (1926-1935 years) and for central durations. However, it has to be noted that equation (12), which is based on this assumption, is approximate and the effect of this departure from normality could be not so significant.

Confidence intervals, with the $5 \%$ level of significance $\left(z_{\alpha / 2}=1.96\right)$, of the mean quantiles $Z_{\theta}$ have been finally evaluated according to equation (18) and results have been reported in Figure 4.

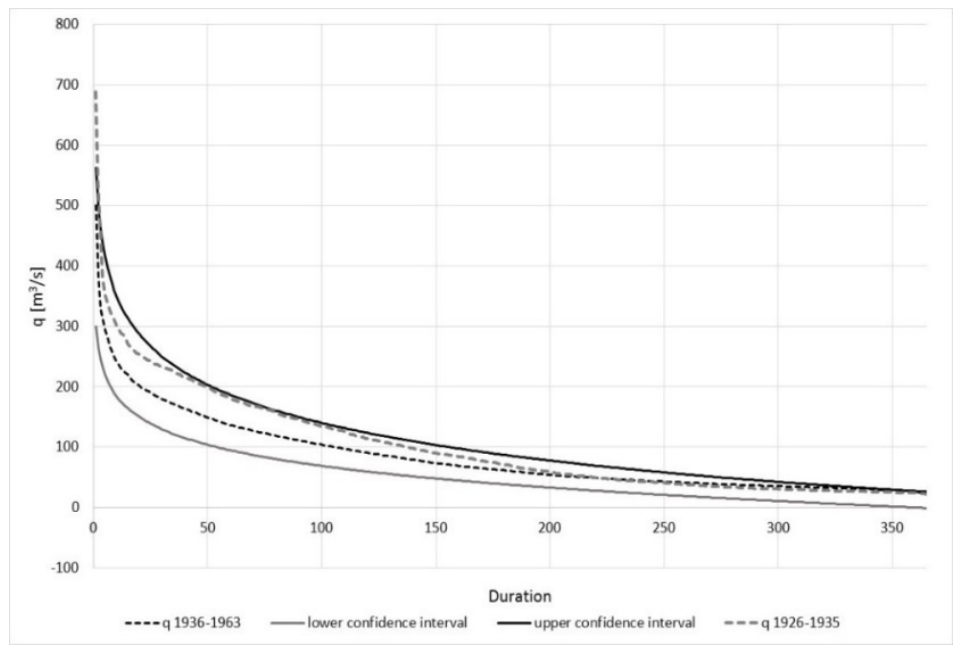

Figure 4: Confidence limits evaluated for the series of regulated flow in the period 1936-1963. The dotted lines represents the mean sample FDCs for the periods 1926-1935 (natural streamflows) and 1936-1963 (regulated streamflows).

The anthropized streamflows, recorded in the period 1936-1963, were used. For the estimation of the standard deviation $s_{q}$, equations (20) and (21) were considered [23]. In the figure, the natural FDC (for the period 1926-1935) is also shown. The frequency factor for the exponential distribution was considered:

$$
K_{T}=\ln (T)-1=\ln \left(\frac{365}{\theta}\right)-1
$$

In Figure 4, it is possible to notice that the confidence limits include not only the regulated, but also the natural flows.

\section{Conclusions}

The assessment of the uncertainty related to the estimation of FDCs is very important in hydrology, but it can result very complex in case of regulated flows. The proposed methodology is able to merge the effects of the intrinsic variability 
in the sample and the uncertainties due to flow anthropic alterations. In particular, the proposed methodology allows to evaluate the confidence intervals for the regulated FDCs, by a multi-parameter estimation of the standard deviation of regulated streamflows. Application to a case study in a catchment in the south Alps gave good results, although a reliable validation of the proposed methodology should be supported by a more extensive application to other case studies.

\section{References}

[1] Montanari, A. \& Brath, A., A stochastic approach for assessing the uncertainty of rainfall-runoff simulations. Water Resources Research, 40, W01106, doi: 10.1029/2003WR002540, 2004.

[2] Di Baldassarre, G. \& Montanari, A., Uncertainty in river discharge observations: a quantitative analysis. Hydrological Earth System Science, 13, pp. 913-921, 2009.

[3] Montanari, A., What do we mean by 'uncertainty'? The need for a consistent wording about uncertainty assessment in hydrology. Hydrological Processes, 21, pp. 841-845, 2007.

[4] Gotzinger, J. \& Bardossy, A., Generic error model for calibration and uncertainty estimation of hydrological models. Water Resources Research, 44, W00B07, doi: 10.1029/2007WR006691.

[5] Bonta, J.V.\& Cleland, B., Incorporating natural variability, uncertainty, and risk into water quality evaluations using duration curves. Journal of the American Water Resources Association, pp. 1481-1496, 2003.

[6] Fekete, B.M. \& Vorosmarty, C.J., Uncertainties in Precipitation and Their Impacts on Runoff Estimates. Journal of Climate, 17, pp. 294-304, 2004.

[7] McMillan, H., Krueger, T. \& Freer, J., Benchmarking observational uncertainties for hydrology: rainfall, river discharge and water quality. Hydrological Processes, 26, pp. 4078-4111, 2012.

[8] Boorman, D.B. \& Sefton, C.E., Recognising the uncertainty in the quantification of the effects of climate change on the hydrological response, Climate Change, 35, pp. 415-434, 1997.

[9] Minville, M., Brissette, F. \& Leconte, R., Uncertainty of the impact of climate change on the hydrology of a Nordic watershed. Journal of Hydrology, 358, pp. 70-83, 2008.

[10] Vogel, R.M., Fennessey, N.M., Flow-duration curves. I: New interpretation and confidence intervals. Journal of Water Resources Planning and Management, 120(4), pp. 485-504, 1994.

[11] Castellarin, A., Galeati, G., Brandimarte, L., Montanari, A., Brath, A., Regional flow-duration curves: reliability for ungauged basins. Advances in Water Resources, 27, pp. 953-965, 2004.

[12] Yu, P.S., Yang, T.C., Wang, Y.C., Uncertainty Analysis of Regional Flow Duration Curves. Journal of Water Resources Planning and Management, 128, pp. 424-430, 2002.

[13] Hamilton, S., Sources of Uncertainty in Canadian Low Flow Hydrometric Data. Canadian Water Resources Journal, 33(2), pp. 125-136, 2008. 
[14] Chow, V.T., Maidment, D.R., Mays, L.W., Chow, V.T., Maidment, D.R., Mays, L.W. Applied Hydrology. McGraw-Hill Series in Water Resources and Environmental Engineering. McGraw-Hill: New York. ISBN 0-07010810-2. xiii, 572 pp., 1988.

[15] Moisiello, U., Idrologia Tecnica. La Goliardica Pavese, Pavia. ISBN 887830-269-4. 824 pp., 1999.

[16] De Jong, C., Collins, D., Ranzi, R., Climate and Hydrology in Mountain Areas. John Wiley and Sons Ltd: Chichester, England, 2005.

[17] Shao, Q., Zhang, L., Chen, Y.D., Singh, V.P., A new method for modelling flow duration curves and predicting streamflow regimes under altered landuse conditions. Hydrological Sciences Journal 54(3), pp. 606-622. DOI: 10.1623/hysj.54.3.636, 2009.

[18] Leopold, L.B. Hydrology for urban land planning. A guidebook on the hydrological effects of urban land uses. Geological Survey Circular 554, 1968.

[19] Stephenson, D. Comparison of the water balance for an undeveloped and a suburban catchment. Hydrological Sciences Journal 39(4), pp. 295-307. DOI: 10.1080/02626669409492751, 1994.

[20] Mann, H.B., Non parametric tests against trend. Econometria 13: pp. 245259, 1945.

[21] Kendall, M.G., Rank correlation methods. Griffin: London, 1975.

[22] Richter, B.D., Thomas, G.A. Restoring environmental flows by modifying dam operations. Ecology and Society 12(1), p. 12, 2007.

[23] Dresti, C., Ciampittiello, M., Saidi, H., Becciu, G. The effects of anthropization on ecosystems services in mountain rivers: a case study in western Alps. Environmental Research, Under review.

[24] David, H.A., Order Statistics. John Wiley: New York, 1981. 